\title{
Rational design of hydrogenation catalysts using nitrogen-doped porous carbon
}

\author{
Yuzhuo Chen, Zhe Wang, Shanjun Mao, Yong Wang *
}

\section{Introduction}

Hydrogenation is one of the most important reactions in the chemical and petroleum refining industries. Since Sabatier [1] first studied the hydrogenation of unsaturated organic compounds in the presence of nickel in 1897, different catalysts have been tested for the hydrogenation of a wide range of substances to produce useful chemicals or intermediates. Compared with homogeneous catalysts, heterogeneous catalysts have attracted greater attention due to their easier separation and better handling properties [2]. Among the various heterogeneous catalysts, metal-supported catalysts are widely used in various hydrogenation reactions. Particularly, metal oxides are generally used as supports in consecutive hydrogenation reactions due to their high mechanical strength, whereas carbon supports are often utilized to produce fine medicals owing to their large surface area and acid-alkali resistance.

However, a vast microporous structure in activated carbon is not beneficial for the diffusion of molecules, especially big molecules in fine chemicals [2]. Therefore, the porous structure of carbon materials has to be designed well to increase the mass transfer and catalytic efficiency. On the other hand, active metal species have a large tendency to aggregate and leach when supported on conventional carbon supports such as activated carbon (AC), due to the weak interaction between the metal and AC. Therefore, many researchers have tried to modify carbon supports to enhance this interaction.

Surface modification of carbon materials usually refers to grafting functional groups on the surface or doping heteroatoms (e.g., N, B, S, and P) into the carbon framework [3]. Among such materials, $\mathrm{N}$-doped carbon $(\mathrm{NC})$ receives special interest owing to the similar atomic radii of nitrogen and carbon, which makes the doping process feasible and the resulting materials unique. Since Rideal et al. [4] first reported in 1926 that N atoms in a carbon matrix have a promotional effect on the catalytic activity in oxalic acid oxidation, the influence of nitrogen on the catalytic performance of different metal-supported NC (metal/NC) catalysts has attracted much attention. It has been well-documented that $\mathrm{N}$ doping can regulate the electronic structure of $\mathrm{NC}$ and further influence the catalytic performance.

To date, NC and metal/metal oxide-supported NC composites have been widely applied in hydrogenation, oxidation, coupling, and other reactions. In this paper, we mainly focus on the unique properties, different fabrication methods, and utilization of NC in different metal-supported catalysts for hydrogenation.

\section{Properties of NC}

Generally, N species in NC materials are classified into two categories: chemical nitrogen and structural nitrogen. Chemical nitrogen exists in the form of surface functional groups such as amines and cyanos, whereas structural nitrogen is a part of the whole skeleton in carbon materials, e.g., pyridinic $\mathrm{N}$ and graphitic N (Fig. 1(a)). The form of different $N$ species can be determined using X-ray photoelectron spectroscopy (XPS), owing to the different chemical environments (Fig. 1(b)). Based on experimental and theoretical studies, graphitic, pyridinic, and pyrrolic $\mathrm{N}$ are more stable than other types of $\mathrm{N}$ species, and exhibit possible interactions with active components and/or reactants; hence, they are more important for NC-based catalysts and in heterogeneous catalysis. However, the effect of these species on the catalytic performance is still under debate. To elucidate their influence, density functional theory (DFT) calculations were employed to determine the electronic properties of these $\mathrm{N}$ species in the carbon skeleton and their impact on the whole skeleton.

To more easily establish the structure of carbon containing different $\mathrm{N}$ species, we used a carbon nanoribbon as a model to represent the graphene structure, as shown in Fig. 1(c). In the case of graphitic $\mathrm{N}, \mathrm{N}$ adopts $s p^{2}$ hybridization and each $s p^{2}$ orbital contains one electron of $\mathrm{N}$ and forms a $\sigma$ bond with a $\mathrm{C}$ atom. The other two valence band electrons occupy the unhybridized $\mathrm{p}_{z}$ orbital. One of these two electrons resides in a valence $\pi$-band, whereas the other is donated to the lowest $\pi$ antibonding band, which leads to the n-type property of the graphitic N structure [6]. As shown in Fig. 1(g), the position of the Dirac point is lower than that of the Fermi level. Although $\mathrm{N}$ 
a

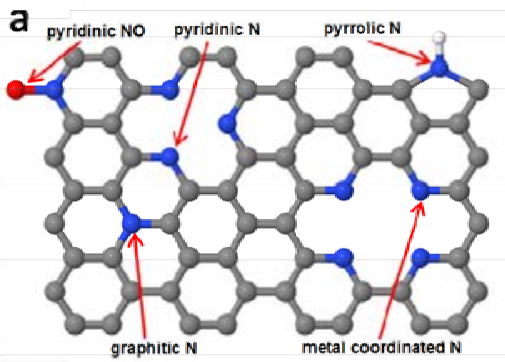

d

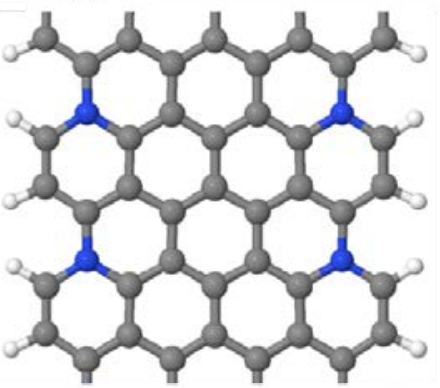

g

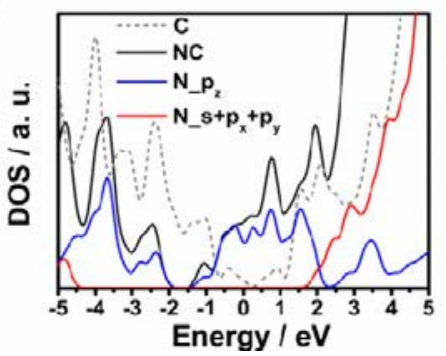

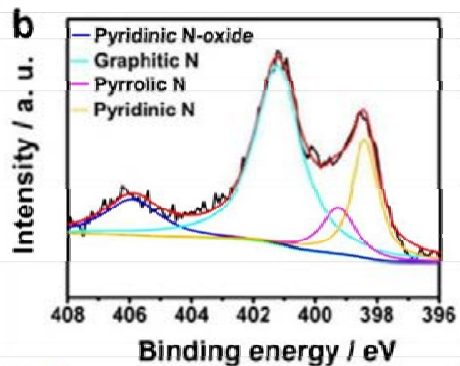

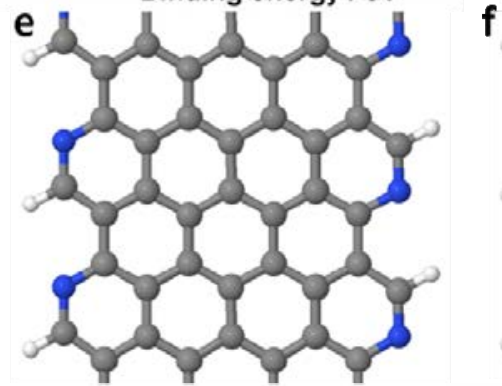

h

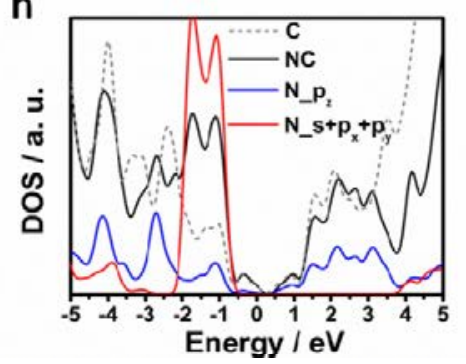

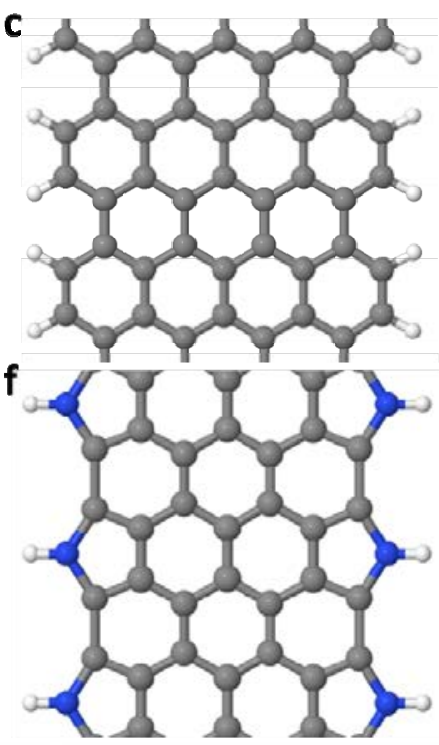

i

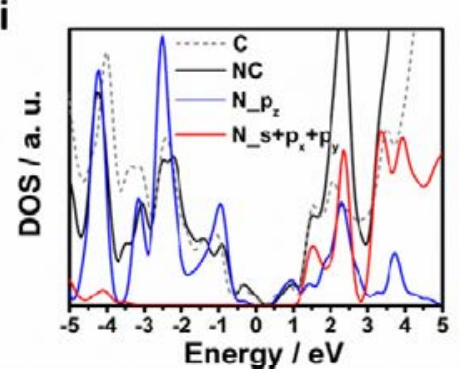

Fig. 1. (a) Various types of nitrogen species in NC materials. (b) XPS spectrum of typical binding energies of different types of N. Reproduced with permission from Ref. [5]. Copyright 2014, American Chemical Society. (c) Structure of carbon nanoribbon used for theoretical calculation, in which unsaturated carbon atoms are saturated by hydrogen atoms. Structures of (d) graphitic N-, (e) pyridinic N-, and (f) pyrrolic N-substituted nanoribbons, in which the white, grey, and blue balls represent hydrogen, carbon, and nitrogen, respectively. Density of states (DOS) of (g) graphitic N-, (h) pyridinic $\mathrm{N}$-, and (i) pyrrolic $\mathrm{N}$-substituted nanoribbons; the dash grey line represents the DOS of the undoped carbon nanoribbon, the solid black line represents the total DOS of the corresponding N-doped nanoribbon, and the blue and red lines represent the projected DOS (pDOS) of the $\mathrm{p}_{z}$ and $\mathrm{s}+\mathrm{p}_{\mathrm{x}}$ $+\mathrm{p}_{\mathrm{y}}$ orbitals ( $s p^{2}$ hybridization) of the corresponding $\mathrm{N}$ species, respectively. The Fermi levels are all aligned to $0 \mathrm{eV}$.

can act as an n-type dopant, owing to its stronger electronegativity, it can withdraw electrons from the three surrounding $\mathrm{C}$ atoms by distorting the electronic density of the N-C $\sigma$-bond toward the $\mathrm{N}$ atom, and show a net charge of $-1.26 \mathrm{e}^{-}$. Moreover, the pDOS of $\mathrm{N}$ near the Fermi level mainly consists of the $\mathrm{p}_{\mathrm{z}}$ orbital.

Pyridinic $\mathrm{N}$ behaves differently compared with graphitic $\mathrm{N}$. To satisfy the minimal energy requirements, one of the valence electrons in the $\mathrm{N}$ atom occupies the unhybridized $\mathrm{p}_{z}$ orbital and participates in the $\pi$-space of graphene, which does not change the Dirac point, unlike in the undoped sample (Fig. $1(\mathrm{~h})$ ), whereas two valence electrons occupy one of the $s p^{2}$ hybridized orbitals and form a dangling $s p^{2}$ orbital. Additionally, the higher electronegativity of $\mathrm{N}$ leads to a net charge of $-1.23 \mathrm{e}^{-}$on the $\mathrm{N}$ atom. Moreover, the pDOS of N near the Fermi level mainly consists of hybrid $s p^{2}$ orbitals. Muhich et al. [6] reported that the highest occupied band (HOMO) of pyridinic $\mathrm{NC}$ consists of $\mathrm{N} s p^{2}$ lone pairs, which are orthogonal to the $\pi$-space of graphene.

In the case of pyrrolic $\mathrm{N}, \mathrm{N}$ adopts $s p^{2}$ hybridization and forms three $\sigma$ bonds with two $\mathrm{C}$ atoms and one $\mathrm{H}$ atom, and the other two valence electrons participate in the valence $\pi$-band and the lowest $\pi$ antibonding band, leading to the n-type property of the pyrrolic N structure. However, owing to the loss of a $\mathrm{C}$ atom in the pyrrolic $\mathrm{N}$ structure, the Dirac point remains comparable to that of the undoped sample (Fig. 1(i)). Despite the n-type property of pyrrolic $\mathrm{N}$, the higher electronegativity of $\mathrm{N}$ leads to a net charge of $-0.95 \mathrm{e}^{-}$on the $\mathrm{N}$ atom. In particular, pyrrolic $\mathrm{N}$ can gradually transform into graphitic $\mathrm{N}$ when the temperature is increased.

Due to the change in the electronic structure caused by the introduced N, NC has several attractive properties such as (1) improved dispersion of the catalyst in aqueous solution [7], owing to the lone pair of electrons of $\mathrm{N}$ that can interact with water molecules via hydrogen bonds; (2) basic sites provided by $\mathrm{N}$ species, which may play an important role in influencing the catalytic performance in some cases (e.g., phenol can interact with $\mathrm{N}$ species through the hydroxy groups via weak $\mathrm{O}-\mathrm{H} \cdot \cdots \mathrm{N}$ interactions [8]); (3) improved metal dispersion and stability due to the strong attraction between $\mathrm{N}$ species and metal/metal precursors/nanoparticles (NPs) [7,9]; and (4) a regulated electronic state of loaded metal NPs, which can in- 


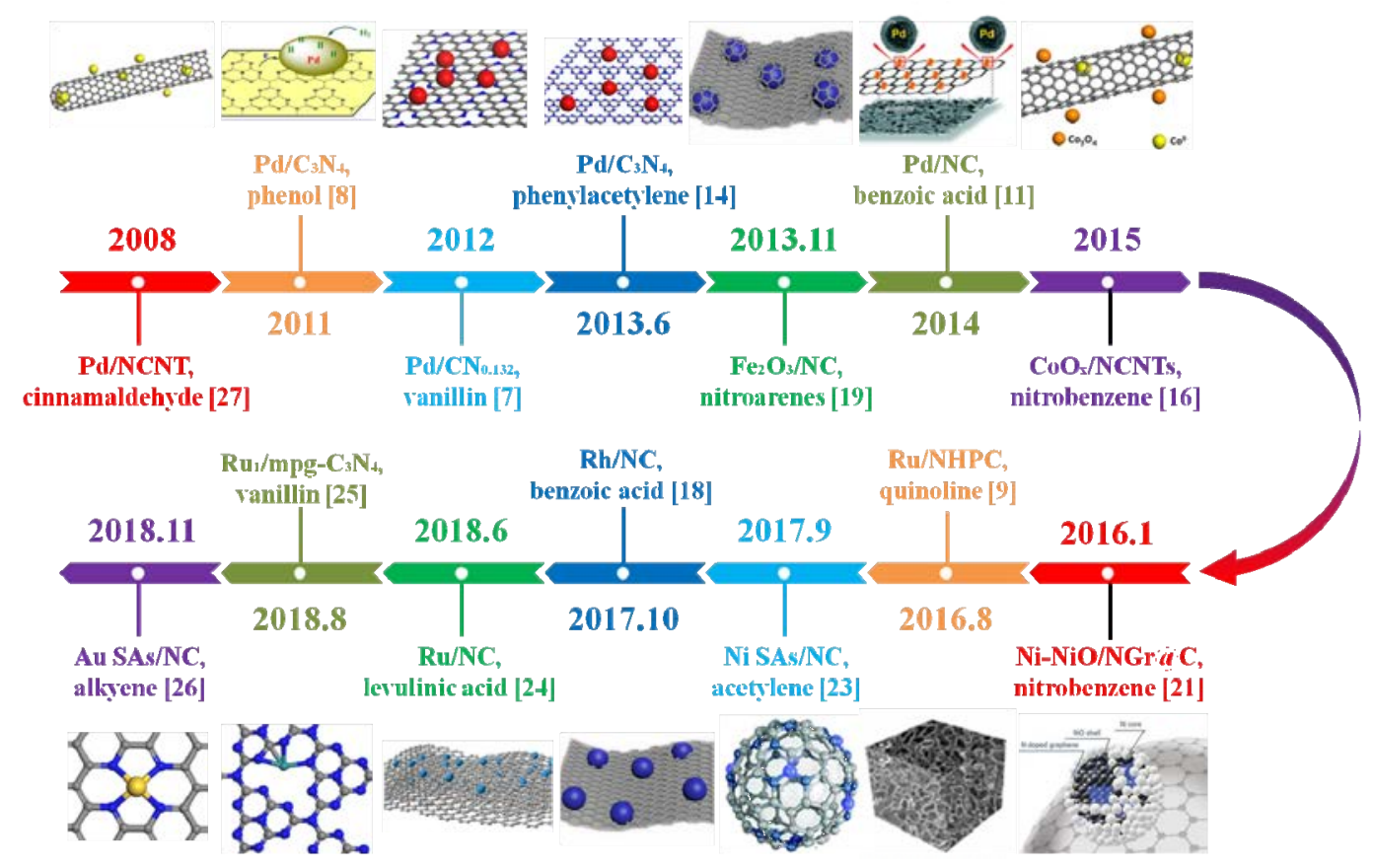

Fig. 2. Different metal-supported NC materials used in hydrogenation. Reproduced with permission from Ref. [16]. Copyright 2015, American Chemical Society. Reprinted with permission from Ref. [15]. Copyright 2013, Elsevier. Reproduced with permission from Ref. [22]. Copyright 2016, Royal Society of Chemistry. Reproduced with permission from Ref. [21]. Copyright 2015, Wiley-VCH. Reproduced with permission from Ref. [9]. Copyright 2016, Royal Society of Chemistry. Reproduced with permission from Ref. [23]. Copyright 2017, Royal Society of Chemistry. Reproduced with permission from Ref. [24]. Copyright 2018, American Chemical Society. Reproduced with permission from Ref. [25]. Copyright 2018, American Chemical Society. Reproduced with permission from Ref. [26]. Copyright 2018, Wiley-VCH.

fluence the catalytic performance [7-9].

\section{Fabrication of porous NC catalysts}

Different fabrication methods of NC materials and metal/NC composites have been developed in the past few decades, and several excellent reviews [2,3] have described these methods in detail. Hence, in this section, we simply categorize these methods rather than describe them thoroughly.

To incorporate nitrogen into a carbon skeleton, three fabrication methods are generally used: post treatment [2,3,27], the template-assisted method [5,7], and direct synthesis [9-12]. Particularly, post treatment is done by pyrolyzing carbon with nitrogen-containing reagents, e.g., $\mathrm{NH}_{3}$ and amines. The template-assisted method involves the utilization of a hard template, such as $\mathrm{SiO}_{2}$ [7] with a certain morphology, to fabricate porous materials, or a soft template such as F127 [5]. Direct synthesis is typically completed by the direct carbonization of nitrogen and carbon-containing precursors such as nitrogen-rich ionic liquids [10] and biomass derivatives [11,12].

In 2015, our group [35] created a novel "leavening" strategy, using biomass as the carbon precursor and $\mathrm{KHCO}_{3}$ as the foaming agent, to synthesize hierarchical porous carbon (HPC) materials with large specific areas (up to $1893 \mathrm{~m}^{2} \mathrm{~g}^{-1}$ ) and excellent hierarchical nanostructures. Furthermore, in-situ $\mathrm{N}$-doping could be realized through a modified method [9], and the N-doped hierarchical porous carbon (NHPC) materials were fabricated using ammonium oxalate as both the nitrogen source and foaming agent. This has several advantages: (1) the preparation method is simple, and easy to be industrialized [35]; (2) the fabrication processes can start from raw biomass [36] or activated carbon [37]; and (3) a hierarchical porous structure, in which macropores can effectively enhance the mass transfer of reactants and products, whereas micro- and mesopores can provide a larger surface area, can be prepared without the assistance of a template [9,35]. This method is indeed a green and sustainable process for the conversion of various types of biomass into functional NHPC materials [38].

With regard to the combination of metal NPs and NC supports, the synthesis methods can be divided into two categories: post treatment and direct synthesis. Specifically, post treatment corresponds to loading a metal precursor onto pre-synthesized NC [7-9,11,13-15], whereas direct synthesis, or one-pot synthesis, involves mixing metal and NC precursors and then pyrolyzing them to obtain the desired materials, wherein the as-prepared catalysts may have embedded or encapsulated structures [16-21].

\section{Porous NC in hydrogenation}

As suggested by the above description, metal supported on NC exhibits better distribution, smaller size, and enhanced electron interaction compared with those of pure carbon, which makes it very favorable in an actual catalytic reaction, especially in hydrogenation. Considering the different metal loading modes, metals supported by NC can be simply divided into four types: supported, embedded, encapsulated, and single-atom anchored catalysts, in which the "supported" mode 
represents conventional metal-supported catalysts, the "embedded" mode stands for metal NPs partially embedded into $\mathrm{NC}$, the "encapsulated" mode implies that metal NPs are entirely covered by $\mathrm{NC}$, and the "single-atom anchored" mode denotes a single metal atom coordinating with certain $\mathrm{N}$ atoms in the NC skeleton.

\subsection{Conventional metal-supported catalysts}

Conventional metal-supported NC catalysts such as Pt/NC and $\mathrm{Pd} / \mathrm{NC}$ have been widely tested in various hydrogenation processes. Generally, such structures are mainly fabricated by post-loading of metal precursors onto pre-synthesized NC supports. Particularly, most NC-supported noble metal catalysts are constructed using this mode. Among the various metals used in conventional supported catalysts, Pd is the most widely used in the hydrogenation of different substrates such as phenol [8], vanillin [7], and benzoic acid (BA) [11].

In 2008, Amadou et al. [27] developed Pd NPs-supported $\mathrm{N}$-doped carbon nanotubes (Pd/NCNTs) for the hydrogenation of cinnamaldehyde. They observed that the Pd/NCNTs showed a higher catalytic activity and selectivity for hydrocinnamaldehyde (HCAL) than those of the undoped counterpart. However, the specific roles of the introduced $\mathrm{N}$ were not well-illustrated. Thereafter, different structures of carbon were doped with $\mathrm{N}$ and tested for the hydrogenation of various substrates.

In 2011, our group firstly proposed the special role of nitrogen in carbon-supported catalysts $\left(\mathrm{Pd} / \mathrm{mpg}^{-} \mathrm{C}_{3} \mathrm{~N}_{4}\right)$; it enables not only a very stable and uniform dispersion of Pd but also the additional electronic activation of the metal NPs, which finally gives rise to a fast and selective hydrogenation to cyclohexanone (Fig. 3) [8]. Thereafter, to investigate the effect of nitrogen doping on phenol hydrogenation, our group [28] utilized different nitrogen-containing ionic liquids (imidazole-type and pyridine-type) to synthesize eight different NC materials with different surface areas, pore sizes, pore volumes, and nitrogen contents. The phenol hydrogenation performances of eight different Pd-supported NC catalysts were investigated. The experimental results showed that the valence state of $\mathrm{Pd}$ was affected by the doped nitrogen atoms, and the content of
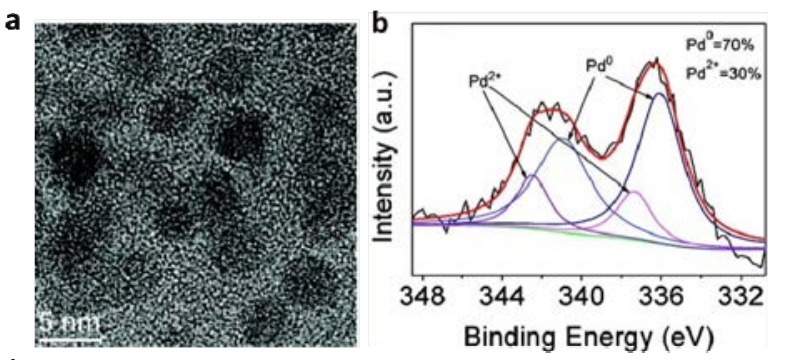

c

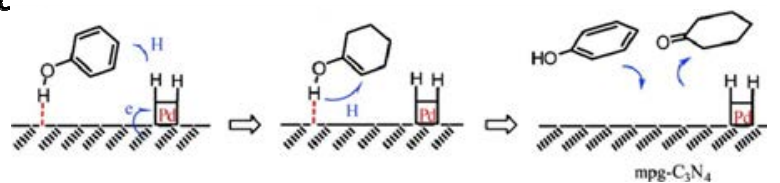

Fig. 3. (a) TEM image of Pd@mpg- $\mathrm{C}_{3} \mathrm{~N}_{4}$. (b) XPS spectrum of Pd@mpg- $\mathrm{C}_{3} \mathrm{~N}_{4}$. (c) Possible reaction mechanism of phenol over Pd@mpg- $\mathrm{C}_{3} \mathrm{~N}_{4}$. Reproduced with permission from Ref. [8]. Copyright 2011, American Chemical Society.
$\mathrm{Pd}^{0}$ was the main factor that affected the catalytic activity. $\mathrm{Pd} / \mathrm{C}_{3} \mathrm{~N}_{4}$ has also been used in the hydrogenation of substrates other than phenol, such as nitriles [13], quinoline [15], and phenylacetylene [14].

$\mathrm{Ru}$ catalysts have attracted much attention for the hydrogenation of aromatics, especially benzene. Our group [9] fabricated a Ru-supported hierarchical porous NC (Ru/NHPC) catalyst. Compared with Ru-supported hierarchical porous carbon (Ru/HPC) and Ru-supported active carbon (Ru/AC), the $\mathrm{Ru} / \mathrm{NHPC}$ catalyst exhibits a better catalytic performance in the aromatic hydrogenation of toluene, with a TOF of $39000 \mathrm{~h}^{-1}$, and quinoline, with TOFs of up to $2858 \mathrm{~h}^{-1}$. There are three main reasons for this: (1) the three-dimensional pore structure of the carrier promotes mass transfer in the reaction process; (2) the doped nitrogen atoms increase the amount of the active component $\mathrm{Ru}^{0}$ by interacting with the supported $\mathrm{Ru}$; and (3) the introduction of nitrogen improves the dispersion of $\mathrm{Ru}$.

Compared with monometallic catalysts, bimetallic catalysts often show unique catalytic performances in hydrogenation due to the mixture of electronic structures of different metal species. Our group [29] developed a Pd-supported NC catalyst (Pd/NC) firstly via a hydrothermal method; it showed an excellent catalytic activity in the hydrogenation of BA, and its activity was significantly higher than that of Pd/AC. Subsequently, by introducing cheaper Ru metal in Pd/NC, the TOF of the bimetallic $\mathrm{Pd}-\mathrm{Ru} / \mathrm{NC}$ catalyst was increased to 6.76 times higher than that of Pd/NC. In addition to Ru-Pd, other bimetallic catalysts, such as Au-Pd [10] and Zn-Pd [34], have also been utilized in the semi-hydrogenation of phenylacetylene and alkynols, respectively.

Although noble metal-supported NC catalysts exhibit good catalytic performance in hydrogenation reactions, their high price and insufficient sources limit their industrialization to a certain extent. Therefore, the development of new and efficient non-noble metal-supported catalysts, such as Fe-, Co-, and Ni-supported catalysts, has recently become the focus of scientific researchers. Our group [30] fabricated Ni/NHPC with a mean Ni NP size of $6.5 \mathrm{~nm}$, and used it for the hydrodeoxygenation of vanillin, with $98 \%$ yield. The excellent activity was ascribed to the modified electronic state of the Ni that interacted with $\mathrm{N}$, and the enhanced mass transfer contributed by the hierarchical porous structure of NHPC. Moreover, Ni/NHPC proved to be very promising for efficient oxygen removal from a wide range of aromatic substrates with carbonyl or $-\mathrm{OH}$ groups.

\subsection{Embedded and encapsulated catalysts}

In addition to the post-loading method, one-pot pyrolysis has also been employed to fabricate carbon-based metal catalysts. In this process, metal NPs embedded in a carbon skeleton or partly covered by carbon layers are often produced. In these local structures, the interaction between the metal and carbon support is much stronger, and can lead to a specific performance in catalytic hydrogenations, as well as enhanced stability of metal NPs.

In 2013, Westerhaus et al. [20] pyrolyzed homogeneous Co 
complexes on activated carbon under high temperatures to fabricate nanoscale cobalt oxide-supported NC catalysts for the hydrogenation of nitrobenzene. This catalyst tolerated numerous reducible functional groups and could be reused several times without a loss in activity. Thereafter, Jagadeesh et al. [19] used the same strategy to develop active $\mathrm{Fe}_{2} \mathrm{O}_{3}$ particles surrounded by NC layers, via the pyrolysis of iron complexes on carbon. This catalyst also showed highly chemoselective hydrogenation activity for the synthesis of numerous nitroarenes with various substituent groups (more than 80 examples) in excellent yields. The activity of the catalyst steadily increased with the pyrolysis temperature from 200 to $800{ }^{\circ} \mathrm{C}$; the material pyrolyzed at $800{ }^{\circ} \mathrm{C}(\mathrm{Fe}-$ phen/C-800) showed the maximum activity, whereas that pyrolyzed at $1000{ }^{\circ} \mathrm{C}$ showed less activity. Fig. 4(a) shows that the $\mathrm{Fe}_{2} \mathrm{O}_{3} \mathrm{NPs}$ in $\mathrm{Fe}-$ phen/C-800 were covered by $\sim 3-5$ layers of $\mathrm{N}$-doped graphene, and both the number of encapsulation graphene layers and the size of the $\mathrm{Fe}_{2} \mathrm{O}_{3}$ NPs increased when the pyrolysis temperature was raised to $1000{ }^{\circ} \mathrm{C}$. In addition to Fe and Co, Pisiewicz et al. [21] fabricated carbon-supported Ni-based NPs modified with $\mathrm{N}$-doped graphene layers (Ni-NiO/NGr@C) (Fig. 4(c)) for the hydrogenation of nitrobenzene.

In 2015, our group [16] developed $\mathrm{Co}^{0}-\mathrm{Co}_{3} \mathrm{O}_{4} / \mathrm{N}$-doped carbon nanotube hybrids $\left(\mathrm{Co}^{0}-\mathrm{Co}_{3} \mathrm{O}_{4} / \mathrm{NCNTs}\right)$ for the hydrogenation of nitrobenzene. This catalyst exhibited excellent activity, and could selectively hydrogenate more than 20 substrates under mild hydrogenation conditions. Theoretical calculations showed that the synergistic effect of $\mathrm{Co}^{0}$ and the doped $\mathrm{N}$ atoms in the catalyst improved the catalytic activity. It is worth noting that a large number of core-shell structures of the metal-carbon layers in the catalyst (Fig. 4(b)) were the reason for the stable catalytic performance. Thereafter, our group [17] prepared a catalyst with porous $\mathrm{N}$-doped graphene layers encapsulating cobalt NPs (Co/NG) via a direct pyrolysis process, for the hydrogenation of diverse quinoline compounds with near-quantitative yields. In addition, our group [22] developed a one-step method to synthesize uniform cobalt NPs supported on porous NC for the hydrogenation of trimethylbenzoquinone (TMBQ). We concluded that the excellent chemoselectivity was due to the preferential desorption of the desired hydrogenation product TMHQ. Moreover, massive Co NPs covered by carbon layers and defects on the outer carbon layers were observed. The defects allowed the reactant to contact with the metal NPs, making the hydrogenation reaction proceed efficiently.

However, the complete encapsulation structure, which always appears in the catalysts prepared via the one-pot method, shows inferior catalytic performance owing to less metal active sites and limited diffusion. In 2017, our group [18] developed an embedded $\mathrm{Rh} / \mathrm{NC}$ catalyst with well-dispersed Rh NPs, via one-pot pyrolysis of chitin and $\left(\mathrm{NH}_{4}\right)_{3} \mathrm{RhCl}_{6}$, for the hydrogenation of BA. The XPS results indicated that the ratio of $\mathrm{Rh}^{0}$ to $\mathrm{Rh}^{3+}$ in the $\mathrm{Rh} / \mathrm{NC}$ samples increased with the pyrolysis temperature. $\mathrm{Rh} / \mathrm{NC}$ pyrolyzed at low temperatures exhibited low catalytic performance, which may have resulted from the low
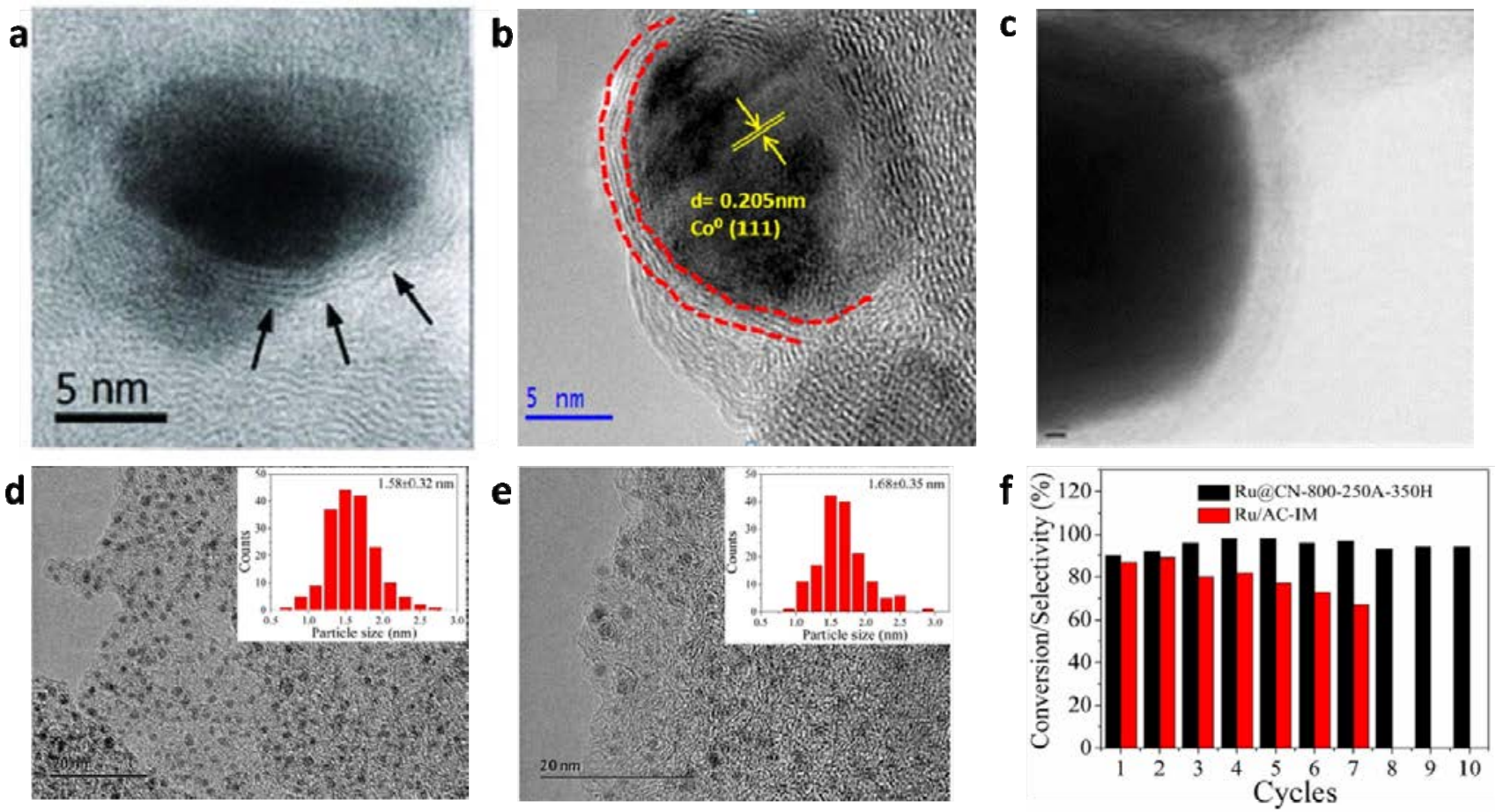

Fig. 4. (a) ABF TEM image of Fe-phen/C-800 from Ref. [19]. Reproduced with permission from AAAS. (b) Representative HRTEM image of CoOx@NCNTs. Reproduced with permission from Ref. [16]. Copyright 2015, American Chemical Society. (c) Bright-field (BF) contrast imaging of Ni-NiO/NGr@C-800. Scale bar = 2 nm. Reproduced with permission from Ref. [21]. Copyright 2015, Wiley-VCH. TEM images and particle size distribution of (d) Ru@NC-800 and (e) Ru@NC-800-250A-350H, in which " $\mathrm{H}$ " and "A" denote the heat treatment process under hydrogen and air atmosphere, respectively. (f) Recycling results of Ru catalysts prepared by various methods; the Ru/AC-IM catalyst was prepared via impregnation, using $\mathrm{AC}$ as the support. Reaction conditions: $1.0 \mathrm{~g} \mathrm{LA}, 5 \mathrm{~mL}$ solvent, $20 \mathrm{mg}$ catalyst, $100{ }^{\circ} \mathrm{C}, 2.0 \mathrm{MPa} \mathrm{H}_{2}$, and 30 min. Reproduced with permission from Ref. [24]. Copyright 2018, American Chemical Society. 
proportion of $\mathrm{Rh}^{0}$ to $\mathrm{Rh}^{3+}$. However, $\mathrm{Rh} / \mathrm{CN}$ pyrolyzed at high temperatures exhibited a lower BA conversion due to the over-encapsulation of Rh NPs into the carbon matrix. Thereafter, an $\mathrm{Ru} / \mathrm{CN}$ catalyst, derived from one-pot pyrolysis of chitin and $\mathrm{Ru}$ metal salt, was developed by our group [24] and utilized in the hydrogenation of levulinic acid (LA). We found that the heat treatment process under both hydrogen and air atmospheres could lead to a significant increase in the exposed proportion of Ru NPs, owing to the hydrogenolysis or combustion of carbon cover-layers near the defects. In addition, Figs. 4(d) and 4(e) show that the heat treatment procedure does not increase the size of the NPs. Moreover, the activity of the catalysts increased with an increase in the reduction and calcination temperatures, owing to the increase in the degree of exposure of the Ru NPs. As shown in Fig. 4(f), the recyclability of $\mathrm{Ru} / \mathrm{NC}$ prepared under $\mathrm{H}_{2}$ and air was far better than that of $\mathrm{Ru} / \mathrm{AC}$ prepared via the impregnation method, owing to the embedded structure of the Ru NPs.

\subsection{Single-atom anchored catalysts}

In the past few decades, single-atom catalysts (SACs) have enabled great progress in various chemical reactions, with excellent chemoselectivity and activity owing to the significant change in catalytic properties derived from the low-coordination environment and quantum size effects of the single metal atom. SACs can be envisaged as the link between homogeneous and heterogeneous systems.

In 2017, Dai et al. [23] prepared single Ni atoms supported on NC (Ni SAs/N-C) (Figs. 5(a) and 5(b)) with the assistance of metal-organic frameworks, and tested them for the selective hydrogenation of acetylene with high activity and selectivity. They envisaged that this Ni SAC can be an effective alternative to Pd-based catalysts, which are widely used for acetylene hydrogenation. Thereafter, Tian et al. [25] prepared single-atom $\mathrm{Ru}$ supported on mesoporous graphitic carbon nitride $\left(\mathrm{Ru}_{1} / \mathrm{mpg}_{-} \mathrm{C}_{3} \mathrm{~N}_{4}\right)$ fabricated via a wet impregnation method, which showed excellent hydrogenation and hydrodeoxygenation performance. Sun et al. [31] fabricated a supported cobalt catalyst with atomically dispersed Co- $\mathrm{N}_{x}$ sites (3.5 wt\% Co) in a mesoporous NC matrix (Co@mesoNC), for the selective catalytic hydrogenation of nitroarenes containing various functional groups. Lin et al. [26] designed single gold atoms supported on $\mathrm{NC}(\mathrm{Au} / \mathrm{NC})$ via the pyrolysis of $\mathrm{HAuCl}_{4}$ on pre-synthesized NC at different temperatures. Figs. 5(c) and 5(d) show that gold species can still remain monoatomic up to $1073 \mathrm{~K}$. In addition, as illustrated in Fig. 5(e), by controlling the pyrolysis temperature, the coordination environment and the oxidation state of the metal can be finely tailored. Furthermore, DFT calculations linked the structure sensitivity for alkynols with $\alpha-\mathrm{OH}$ to the strong interactions between the adsorbed $\alpha$-alkynol molecules and the gold and oxidized 4-pyridinic $\mathrm{N}$ ensemble via the formation of hydrogen bonds.

\subsection{Metal-free catalysts}

The sustainable synthesis of catalytically active metal-free porous NC materials is highly desired owing to the thermal stability, chemical stability in acid, alkali, and organic solvents, high surface area, and low cost of porous NC. Akhmedov et al.
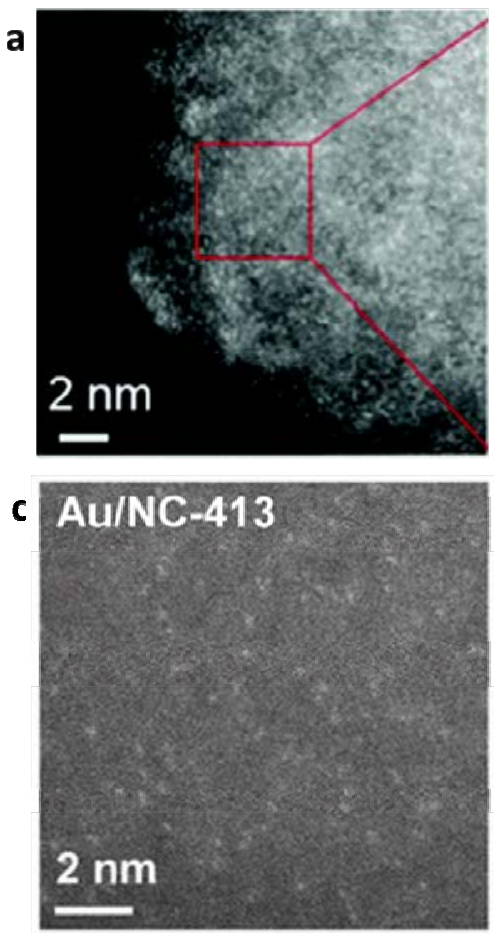

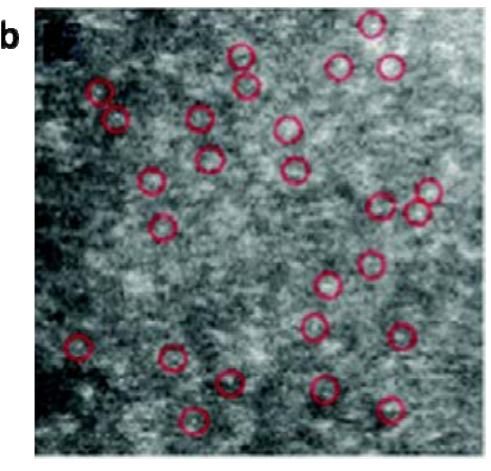

d Au/NC1073

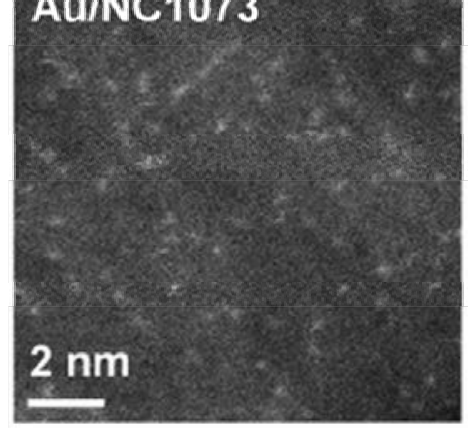

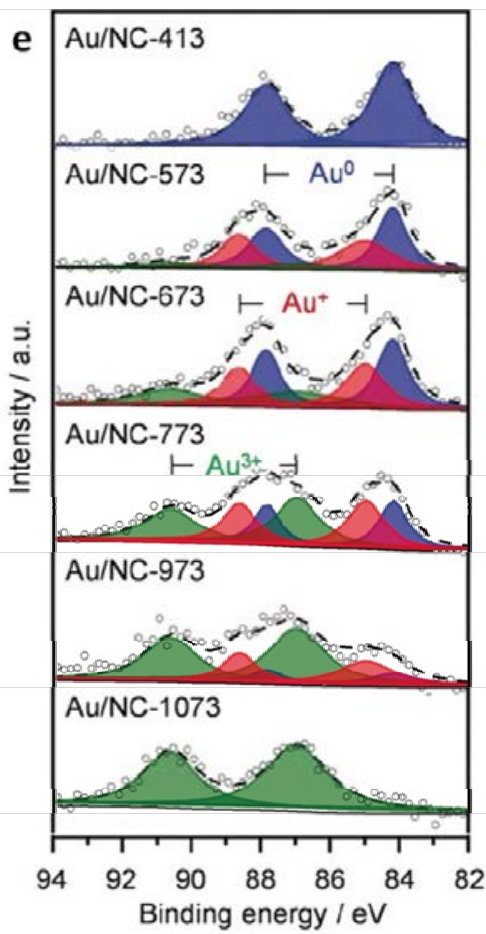

Fig. 5. (a, b) Magnified HAADF-STEM images of Ni SAs/N-C, showing the presence of single Ni atoms in Ni SAs/N-C. Reproduced with permission from Ref. [23]. Copyright 2017, Royal Society of Chemistry. (c, d) Aberration-corrected HAADF-STEM micrographs of Au/NC-T, in which "T" denotes the pyrolysis temperature. (e) Au 4 c core-level XPS spectra of Au/NC-T. Reproduced with permission from Ref. [26]. Copyright 2018, Wiley-VCH. 
[32] fabricated mesoporous polymeric carbon nitride $\left(\right.$ mpg- $\left.\mathrm{C}_{3} \mathrm{~N}_{4}\right)$ and used it for the selective hydrogenation of phenylacetylene to styrene at $250{ }^{\circ} \mathrm{C}$, with $76.4 \%$ yield of styrene in the gas phase. However, the performance of this catalyst was relatively poor at low temperatures. Xiao et al. [33] used low-cost graphitic $\mathrm{C}_{3} \mathrm{~N}_{4}\left(\mathrm{~g}-\mathrm{C}_{3} \mathrm{~N}_{4}\right)$ as a metal-free catalyst for the chemoselective hydrogenation of different functionalized nitroarenes at $70-90{ }^{\circ} \mathrm{C}$, with good yields $(>82 \%)$ in water under visible light. Moreover, this catalyst could be reused multiple times and applied in a gram-scale reaction (86\% yield of aniline).

\section{Perspectives}

From the perspective of synthesis methods, the development of a simple, controllable, and inexpensive method for the preparation of porous NC is the main objective. Firstly, biomass would be the preferred raw material. However, the diversity of biomass needs to be taken into consideration, because there may be a huge difference among the carbon materials derived from various raw biomass samples. Secondly, templates should be abandoned or used as little as possible. To this end, the "foaming method" [9] we developed can help create HPC from raw biomass with a low-cost foaming agent, and has large-scale industrial application prospects; the waste carbon in industry can also be activated again and doped with nitrogen at the same time.

Noble metal-supported porous NC catalysts have been proven to exhibit excellent catalytic efficiency in many catalytic hydrogenation reactions. For example, the Pd/NC and Pt/NC catalysts developed by our group have been industrialized in Zhejiang NHC Company Ltd. at a ton scale and used for the selective hydrogenation of key intermediates in vitamin synthesis. The Pd/NHPC catalysts have been employed for the selective hydrogenation of unsaturated ketone and TMBQ in Vitamin E synthesis [39]. Moreover, these catalysts can be reused more than 30 times for the selective hydrogenation of sulfur-containing intermediates in the production of Vitamin $\mathrm{H}$, which can reduce the cost by a large margin. The future development of this area can be divided into three parts: (1) uncovering the interaction between $\mathrm{N}$ species in the carbon matrix and the metal species, from both theoretical and experimental aspects; (2) establishing an elaborate structure-performance relationship of NC-supported noble metal catalysts in various reactions; and (3) expanding their hydrogenation applications for the manufacture of other fine chemicals and pharmaceuticals.

Currently, non-noble metal-supported porous NC catalysts are very difficult to use in industrial-scale applications. The main reason is that their catalytic activity is far lower than that of noble metals. However, such catalysts can be further developed, with improved catalytic activity, by fabricating SACs, alloy catalysts [40], etc. At the same time, applications in some new hydrogenation reactions can be continuously explored. Future industrial applications can be also expected.

Furthermore, metal-free NC catalysts have attracted extensive attention in recent years. This idea draws lessons from the
B-N acid-base pair in organic chemistry; these Lewis pairs can heterolytically split $\mathrm{H}_{2}$ to produce $\mathrm{H}^{+} / \mathrm{H}^{-}$pairs, which subsequently serve as the active species for the hydrogenation of different substrates. This has a certain value from the perspective of basic research. However, due to the harsh reaction conditions and the relatively low activity of metal-free catalysts compared with those of metal-supported catalysts, their prospective industrialization value is not as good as that of metal-supported catalysts.

\section{Acknowledgments}

Financial support from the National Natural Science Foundation of China (21622308, 21802120), the Key Program Supported by the Natural Science Foundation of Zhejiang Province, China (LZ18B060002), and the Fundamental Research Funds for the Central Universities (2017XZZX002-16) are greatly appreciated.

\section{Yong Wang}

Advanced Materials and Catalysis Group, Institute of Catalysis, Department of Chemistry, Zhejiang University, Hangzhou, 310028, Zhejiang, China

E-mail: chemwy@zju.edu.cn

Received 22 January 2019

Published 5 July 2019

DOI: S1872-2067(19)63353-X

\section{References}

[1] E. K. Rideal, J. Chem. Soc., 1951, 1640-1647.

[2] M. M. Li, F. Xu, H. R. Li, Y. Wang, Catal. Sci. Technol, 2016, 6, 3670-3693.

[3] Y. L. Cao, S. J. Mao, M. M. Li, Y. Q. Chen, Y. Wang, ACS Catal., 2017, 7, 8090-8112.

[4] E. K. Rideal, W. M. Wright, J. Chem. Soc., 1926, 1813-1821.

[5] S. P. Wang, C. L. Han, J. Wang, J. Deng, M. L. Zhu, J. Yao, H. R. Li, Y. Wang, Chem. Mater., 2014, 26, 6872-6877.

[6] C. L. Muhich, J. Y. Westcott, T. C. Morris, A. W. Weimer, C. B. Musgrave, J. Phys. Chem. C, 2013, 117, 10523-10535.

[7] X. Xu, Y. Li, Y. T. Gong, P. F. Zhang, H. R. Li, Y. Wang, J. Am. Chem. Soc., 2012, 134, 16987-16990.

[8] Y. Wang, J. Yao, H. R. Li, D. S. Su, M. Antonietti, J. Am. Chem. Soc., 2011, 133, 2362-2365.

[9] M. H. Tang, J. Deng, M. M. Li, X. F. Li, H. R. Li, Z. R. Chen, Y. Wang, Green Chem., 2016, 18, 6082-6090.

[10] P. F. Zhang, J. Y. Yuan, T. P. Fellinger, M. Antonietti, H. R. Li, Y. Wang, Angew. Chem. Int. Ed., 2013, 52, 6028-6032.

[11] X. Xu, M. H. Tang, M. M. Li, H. R. Li, Y. Wang, ACS Catal., 2014, 4, 3132-3135.

[12] P. F. Zhang, Y. T. Gong, Z. Z. Wei, J. Wang, Z. Y. Zhang, H. R. Li, S. Dai, Y. Wang, ACS Appl. Mater. Interfaces, 2014, 6, 12515-12522.

[13] Y. Li, Y. T. Gong, X. Xu, P. F. Zhang, H. R. Li, Y. Wang, Catal. Commun., 2012, 28, 9-12.

[14] D. S. Deng, Y. Yang, Y. T. Gong, Y. Li, X. Xu, Y. Wang, Green Chem., 2013, 15, 2525-2531.

[15] Y. T. Gong, P. F. Zhang, X. Xu, Y. Li, H. R. Li, Y. Wang, J. Catal., 2013, 297, 272-280.

[16] Z. Z. Wei, J. Wang, S. J. Mao, D. F. Su, H. Y. Jin, Y. H. Wang, F. Xu, H. R. 


\title{
Graphical Abstract
}

Chin. J. Catal., 2019, 40: 971-979 doi: S1872-2067(19)63353-X

Rational design of hydrogenation catalysts using nitrogen-doped porous carbon

Yuzhuo Chen, Zhe Wang, Shanjun Mao, Yong Wang *

Zhejiang University

This perspective discusses the microstructure of N-doped carbon, the fabrication of various $\mathrm{N}$-doped carbon materials, and the application of $\mathrm{N}$-doped carbon-based metal catalysts in different hydrogenation reactions. The image shows the structure of $\mathrm{N}$-doped carbon and its application in hydrogenation.

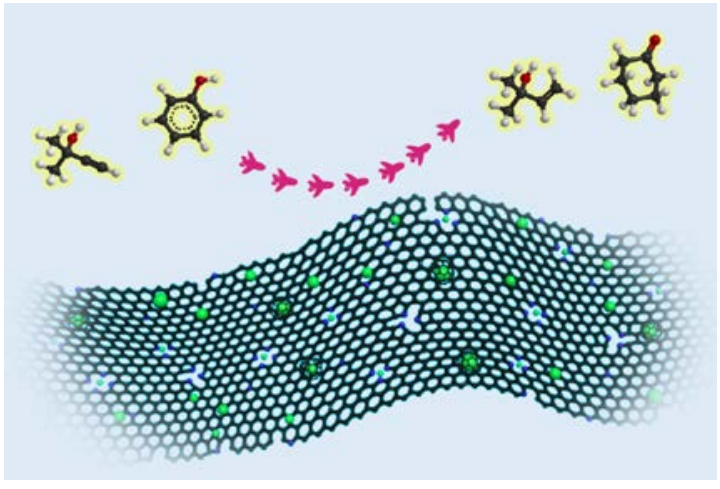

Li, Y. Wang, ACS Catal., 2015, 5, 4783-4789.

[17] Z. Z. Wei, Y. Q. Chen, J. Wang, D. F. Su, M. H. Tang, S. J. Mao, Y. Wang, ACS Catal., 2016, 6, 5816-5822.

[18] Y. L. Cao, M. H. Tang, M. M. Li, J. Deng, F. Xu, L. Xie, Y. Wang, ACS Sustain. Chem. Eng., 2017, 5, 9894-9902.

[19] R. V. Jagadeesh, A. E. Surkus, H. Junge, M. M. Pohl, J. Radnik, J. Rabeah, H. M. Huan, V. Schünemann, A. Brückner, M. Beller, Science, 2013, 342, 1073-1076.

[20] F. A. Westerhaus, R. V. Jagadeesh, G. Wienhöfer, M. M. Pohl, J. Radnik, A. E. Surkus, J. Rabeah, K. Junge, H. Junge, M. Nielsen, A. Brückner, M. Beller, Nat. Chem., 2013, 5, 537-543.

[21] S. Pisiewicz, D. Formenti, A. E. Surkus, M. M. Pohl, J. Radnik, K. Junge, C. Topf, S. Bachmann, M. Scalone, M. Beller, ChemCatChem, 2016, 8, 129-134.

[22] D. F. Su, Z. Z. Wei, S. J. Mao, J. Wang, Y. Li, H. R. Li, Z. R. Chen, Y. Wang, Catal. Sci. Technol, 2016, 6, 4503-4510.

[23] X. Y. Dai, Z. Chen, T. Yao, L. R. Zheng, Y. Lin, W. Liu, H. X. Ju, J. F. Zhu, X. Hong, S. Q. Wei, Y. E. Wu, Y. D. Li, Chem. Commun., 2017, 53, 11568-11571.

[24] Y. L. Cao, B. W. Zhao, X. B. Bao, Y. Wang, ACS Catal., 2018, 8, 7077-7085.

[25] S. B. Tian, Z. Y. Wang, W. B. Gong, W. X. Chen, Q. C. Feng, Q. Wu, C. Chen, C. Chen, Q. Peng, L. Gu, H. J. Zhao, P. Hu, D. S. Wang, Y. D. Li, J. Am. Chem. Soc., 2018, 140, 11161-11164.

[26] R. Lin, D. Albani, E. Fako, S. K. Kaiser, O. V. Safonova, N. López, J. Pérez-Ramírez, Angew. Chem. Int. Ed., 2019, 58, 504-509.
[27] J. Amadou, K. Chizari, M. Houllé, I. Janowska, O. Ersen, D. Bégin, C. Pham-Huu, Catal. Today, 2008, 138, 62-68.

[28] X. Xu, H. R. Li, Y. Wang, Chemcatchem, 2014, 6, 3328-3332.

[29] M. H. Tang, S. J. Mao, M. M. Li, Z. Z. Wei, F. Xu, H. R. Li, Y. Wang, ACS Catal., 2015, 5, 3100-3107.

[30] M. M. Li, J. Deng, Y. K. Lan, Y. Wang, Chemistryselect, 2017, 2, 8486-8492.

[31] X. Sun, A. I. Olivos-Suarez, D. Osadchii, M. J. V. Romero, F. Kapteijn, J. Gascon, J. Catal., 2018, 357, 20-28.

[32] V. Akhmedov, A. Aliyev, M. Bahmanov, V. Ahmadov, D. Tagiyev, Appl. Catal. A, 2018, 565, 13-19.

[33] G. Xiao, P. F. Li, Y. L. Zhao, S. N. Xu, H. J. Su, Chem-Asian J., 2018, 13, 1950-1955.

[34] L. F. Shen, S. J. Mao, J. Q. Li, M. M. Li, P. Chen, H. R. Li, Z. R. Chen, Y. Wang, J. Catal., 2017, 350, 13-20.

[35] J. Deng, T. Y. Xiong, F. Xu, M. M. Li, C. L. Han, Y. T. Gong, H. Y. Wang, Y. Wang, Green Chem., 2015, 17, 4053-4060.

[36] J. Deng, T. Y. Xiong, H. Y. Wang, A. M. Zheng, Y. Wang, ACS Sustain. Chem. Eng., 2016, 4, 3750-3756.

[37] Y. Q. Chen, X. F. Li, Z. Z. Wei, S. J. Mao, J. Deng, Y. L. Cao, Y. Wang, Catal. Commun., 2018, 108, 55-58.

[38] J. W. Qi, W. D. Zhang, L. Xu, Chem. Eur. J., 2018, 24, 18097-18105.

[39] Z. Wang, S. J. Mao, H. R. Li, Y. Wang, Acta Phys-Chim. Sin., 2018, 34, 598-617.

[40] X. F. Li, Z. Wang, S. J. Mao, Y. Q. Chen, M. H. Tang, H. R. Li, Y. Wang, Chin. J. Chem., 2018, 36, 1191-1196.

\section{基于氮掺杂多孔炭的加氢催化剂的理性设计}

\author{
陈宇卓, 王 哲, 毛善俊, 王 勇*
}

浙江大学催化研究所先进材料与催化课题组, 浙江杭州 310028

摘要: 选择性加氢反应是化学化工领域中最具挑战性的反应之一. 针对选择性加氢反应来设计具有工业应用价值的负载 型纳米催化剂一直是学术界和工业界的研究热点与难点. 载体是负载型催化剂的重要组成部分, 在不同类型的载体中, 炭 载体因其来源广、成本低、耐酸碱、具有高比表面积而被广泛采用. 但是, 由于炭材料本身相对惰性, 炭与负载的金属之 间相互作用较弱; 此外, 碳前驱体的种类甚至产地对炭载体性能影响也非常大, 导致催化剂活性及稳定性难以满足工业要 求, 从而严重限制了炭负载型催化剂的发展. 近年来, 氮掺杂炭由于其独特的性质受到了广泛的关注, 大量的研究证实氮 原子的掺入有助于提高炭负载型纳米催化剂的催化效率. 本文将重点关注氮掺杂多孔炭负载型催化剂在选择性加氢反应 
中的应用; 最后, 将讨论并展望如何基于氮掺杂炭理性设计新型负载型纳米金属催化剂.

氮掺杂炭材料中的氮主要可分为石墨氮、吡啶氮、吡咯氮和氨基氮. 氮的引入一方面可改变炭材料的局域电子密度, 引发电子在载体与活性组分之间的重新分配, 电子转移的方向和程度可通过氮掺杂形式(如吡啶型或石墨型氮等)及浓度进 行调节, 从而实现对活性组分电子结构的调控; 另一方面, 提供了孤对电子用于形成氢键网络, 从而调节了催化剂的亲水 性, 改善了催化剂在反应体系中的分散性. 而且丰富的氮物种可为活性组分提供了稳定的针定位点, 从而提高了活性组分 在炭载体上的分散度和稳定性. 此外, 部分氮物种为催化剂提供了碱性位点, 可作为固体碱参与反应, 丰富了氮掺杂炭负 载型催化剂的应用范围.

本文将氮掺杂炭负载型催化剂分为以下四种类型: 传统负载型、包覆型、镶嵌型以及单原子催化剂. 传统负载型催化 剂即以氮掺杂炭材料为载体, 采用浸渍法或液相还原法等将活性组分负载其上, 该类型催化剂已经被广泛研究和使用. 对 于包覆型和镶嵌型催化剂, 其金属和载体间的相互作用要强于传统炭负载型催化剂, 这种强相互作用可有效提升催化剂稳 定性, 更能使某些高活性亚稳相稳定存在, 进而大幅增强催化性能. 但是炭层的过度包覆会导致暴露的金属活性位点减少, 进而影响催化剂的性能. 最近, 炭负载型单原子催化剂得到迅速发展, 它有着独特的配位环境和微观结构, 众多单原子催 化剂(如镍、钉、金等)已在选择性加氢反应中展现出优异的催化性能, 且在某些反应中表现出独特的选择性.

最后, 本文讨论了氮掺杂炭负载型加氢催化剂未来的发展方向. 原始生物质是氮掺杂炭的理想原料, 且制备过程应尽 量避免模板剂的使用. 丰富氮掺杂炭材料的形貌和微观结构, 以应对不同的反应需求是今后的重点发展方向. 贵金属催化 剂拥有优异的催化性能, 如何提升其稳定性是急需解决的问题. 非贵金属催化剂的活性相对较低, 多组分协同催化是提升 其性能的有效方法, 进一步的工业应用也值得期待. 不含金属的氮掺杂炭直接催化加氢反应需要极为苛刻的反应条件, 其 工业应用前景相对较低.

关键词: 负载型催化剂; 氮掺杂炭; 催化选择性加氢; 碳基催化剂; 化工

收稿日期: 2019-01-22. 接受日期: 2019-03-07. 出版日期: 2019-07-05.

*通讯联系人. 电子邮箱: chemwy@zju.edu.cn

基金来源：国家自然科学基金(21622308，21872121); 浙江省自然科学基金重点项目(LZ18B060002); 中央高校基本科研业务费 (2017XZZX002-16).

本文的电子版全文由Elsevier出版社在ScienceDirect上出版(http://www.sciencedirect.com/science/journal/18722067). 